\title{
Spinal Cord Neuroblastoma
}

National Cancer Institute

\section{Source}

National Cancer Institute. Spinal Cord Neuroblastoma. NCI Thesaurus. Code C5155.

A neuroblastoma that affects the spinal cord. 